\title{
AN UNUSUAL CASE OF HUGE SACCROCOCCYGEAL MENINGOCELE
}

Shireen $\mathrm{A}^{1}$, Lalitha Shivanna ${ }^{2}$

\section{HOW TO CITE THIS ARTICLE:}

Shireen A, Lalitha Shivanna "An Unusual Case of Huge Saccrococcygeal Meningocele". Journal of Evolution of Medical and Dental Sciences 2014; Vol. 3, Issue 57, October 30; Page: 13054-13056,

DOI: $10.14260 /$ jemds/2014/3735

ABSTRACT: Meningocele is the least common form of spina bifida. It is most common among female fetus. ${ }^{1}$ Mening ocele has a better prognosis than meningomyelocele since it does not contain neural element. $^{2}$

INTRODUCTION: Spina bifida meningocele and myelomeningocele are among the most common birth defects, with worldwide incidence of about $1: 1000^{2}$ births. The meningocele also called meningeal cyst is the least common form of spina bifida. In this form vertebra develops normally, but the meninges are forced into the gaps between the vertebrae. As the nervous system remain undamaged, individuals unlikely to suffer long term health problems. Causes of meningocele include teratoma and other tumors of the sacrococcyx and of the pre sacral space and Currarino syndrome. The most common location of the malformations is the lumbar and sacral areas. The mothers who had prior spina bifida can be decreased by up to $70 \% 3$ by folic acid supplementations.

CASE REPORT: A 22yrs old lady, G2P1L1 with 38wks + 5days gestation came in active labor. The scan done at 7 mnths of amennorhea showed a single live intrauterine gestation of 27-28wks in cephalic presentation with good cardiac activity and adequate liquor with estimated fetal weight $1.5 \mathrm{~kg}$ corresponding to gestational age with sacrococcygeal meningocele. The fetal calvaria, spine, skin over spine, face, heart, stomach, both kidneys, bladder appeared normal.

AFI was $15 \mathrm{~cm}$. There was a huge mass arising from the saccrococcygeal region with few loculations measuring $9.2 \times 6.5 \mathrm{~cm}$ suggestive of sacrococcygeal meningocele. There were no other associated anomalies. This is the ultrasound picture showing the cystic swelling arising from lower end the spine. Her obstetric history suggested, she was married for 3yrs \& it's a non-consanguineous marriage. In previous pregnancy patient had delivered an alive healthy female baby of $2.75 \mathrm{~kg}$ at term vaginally.

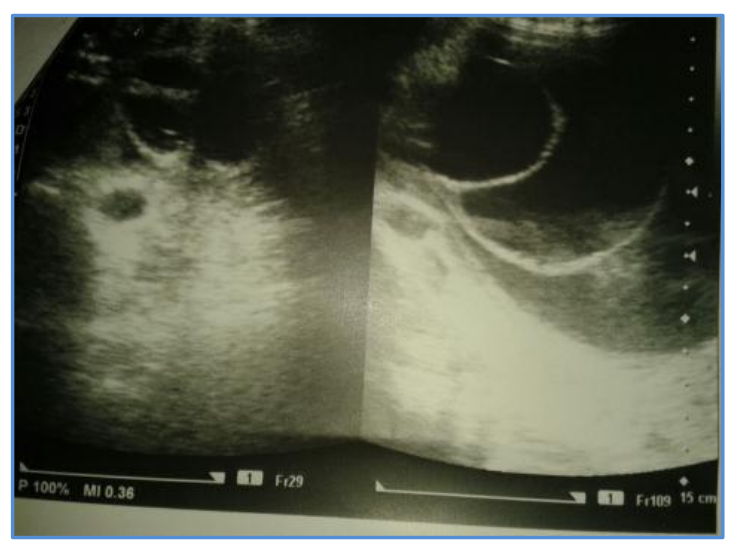


In this pregnancy patient had regular ANC in a PHC. There is no h/o taking folic acid in the first trimester. When patient had come to us at 8months of amenorrhea with the above scan report she was suggested a confirmation scan at higher center to arrive at a proper diagnosis but failed to get it done due to financial constraint. She directly came to us at term in active labor. It was a spontaneous onset labor progressed uneventfully. In the second stage of labor there was delay in the delivery of after coming buttocks which was followed by the delivery of sacrococcygeal mass.

The baby born was a female child weighing $4.04 \mathrm{~kg}$ along with the mass. The mass alone weighed $1.04 \mathrm{~kg}$. On examination there was a huge thick pedunculated mass arising from the sacrococcygeal region, measuring $25 \times 25 \mathrm{~cm}$, cystic in nature, translucency test positive, no impulse transmitted on crying. There was a discrete swelling at the level of L1 -L2 measuring $3 \times 5 \mathrm{~cm}$, firm in consistency about which was not commented in the antenatal scan. The over lying skin was normal with no evidence of tuft of hair/dimpling of skin/birth mark suggestive of spina bifida occulta. Baby was moving all forelimbs. The APGAR was $10 / 10$ at birth.

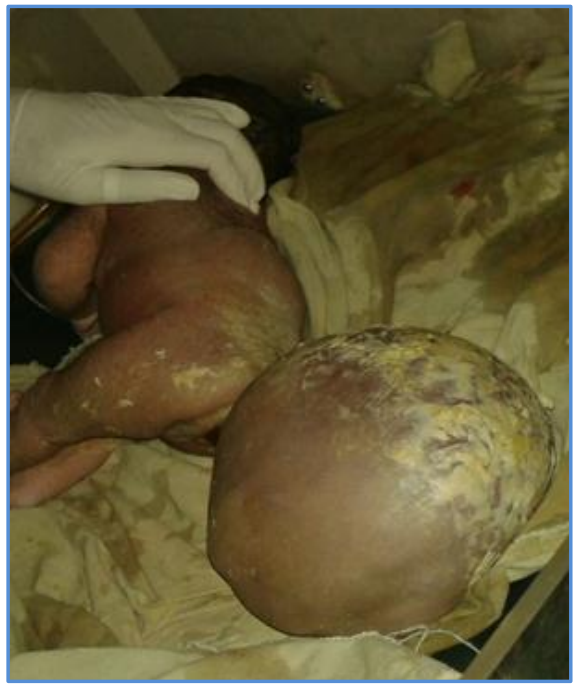

Baby was shifted to NICU for further evaluation. Diagnosis of saccrococcygeal meningocele was made and posted for surgery after $1 \mathrm{wk}$ of birth.

DISCUSSION: Causes of meningocele include teratoma and other tumors of the sacrococcyx and other tumors of the sacrococcyx and of the presacral space and Currarino syndrome 4 . The most common location of the malformations is the lumbar and sacral areas. The differential diagnosis for sacrococcygeal mass is sacrococcygeal teratoma, terminal myelocystocele, meningomyelocele, meningocele, lipoma, hamartoma, lymphangioma, hemangioma, chordoma and ependydoma 4 .

CONCLUSION: Even though spina bifida meningocele is among most common birth defect, this case presenting with giant meningocele at rarest site of the spine sacrococcygeal junction. Unusually this fetus had cephalic presentation at term and delivered vaginally with minimal assistance. If the mothers are supplemented with folic acid, recurrence of spina bifida in subsequent pregnancy can be decreased by up to $70 \%$. 


\section{REFERENCES:}

1. Yu J. A, Sohaey R, Kennedy A. M. and Selden N. R. Terminal Myelo cystocele and Sacrococcygeal Teratoma, AJNR June2007 28: 1058 -1060.

2. Feltes $\mathrm{CH}$, Fountas KN, Dimopoulos VG,et al. Cervical meningocele in association with spinal abnormalities. Childs Nerv Syst 20: 357-361, 2004.

3. D. Shedid, E. P. Roger, and E. C. Benzel, Sacral meningocele: diagnosis and treatment, Seminars in Spine Surgery, vol.18, no.3, pp.161-167, 2006.

4. Matiour H, Woolley M, Trivedi S, et al. Sacrococcygealtumors. J Pediatr Surg. 2004: 824 -6.

\section{AUTHORS:}

1. Shireen A.

2. Lalitha Shivanna

\section{PARTICULARS OF CONTRIBUTORS:}

1. Resident, Department of OBG, Mysore Medical College \& Research Institute, Mysore, Karnataka, India.

2. Professor \& HOD, Department of OBG, MIMS, Mandya.

\section{NAME ADDRESS EMAIL ID OF THE CORRESPONDING AUTHOR:}

Dr. Shireen A,

Resident, Department of OBG, Mysore Medical College \&

Research Institute, Mysore,

Karnataka, India

Email: karani_gk@gmail.com

Date of Submission: 22/10/2014.

Date of Peer Review: 23/10/2014.

Date of Acceptance: 30/10/2014.

Date of Publishing: 30/10/2014. 